\title{
Role of AMPK and its possible interactions in metformin therapy and physical exercise-Research perspectives
}

\author{
Lucas Eduardo Campos de Oliveira ${ }^{1}$, Luiz Augusto da Silva ${ }^{2,3^{*}}$, Jéssica Wouk ${ }^{3}$, Vinícius Müller Reis Weber ${ }^{1}$, \\ Camila da Luz Eltchechem ${ }^{3}$, Pablo de Almeida ${ }^{2}$, Julio Cesar Lacerda Martins ${ }^{2}$, Flavia Angela Servat Martins ${ }^{2}$, \\ Carlos Ricardo Maneck Malfatti ${ }^{1,3}$, Raul Osiecki ${ }^{4}$ \\ ${ }^{1}$ Physical Education Department, Midwest State University of Paraná, Guarapuava, Paraná, Brazil. \\ ${ }^{2}$ Physical Education Collegiate, Faculdade Guairacá, Guarapuava, Paraná, Brazil. \\ ${ }^{3}$ Post-graduation of Pharmaceutical Science, Midwest State University of Paraná, Guarapuava, Paraná, Brazil. \\ ${ }^{4}$ Physical Education Department, Federal university of Paraná, Curitiba, Paraná, Brazil.
}

\author{
ARTICLE INFO \\ Article history: \\ Received on: 03/06/2017 \\ Accepted on: 20/08/2017 \\ Available online: 30/10/2017 \\ Key words: \\ AMPK, Diabetes, Physical \\ Exercise.
}

\begin{abstract}
Insulin resistance results in increased blood glucose, called hyperglycemia, leading to the onset of diabetes mellitus. A better function in glucose uptake caused by metformin and physical exercise are interesting strategies for the control of hyperglycemia. Studies demonstrate expressive and beneficial results of physical exercise associated with metformin in response to the activation of a protein called AMPK, which stimulates Glut4 translocation, which improves the glucose sensitivity and hyperglycemia reduction. The present review seeks understanding on the effects of physical exercise and Metformin on the AMPK enzyme in the metabolism of glucose in diabetic people.
\end{abstract}

\section{INTRODUCTION}

It is well known that type 2 diabetes mellitus (T2DM) is a chronic degenerative disease that can cause a number of deleterious effects on the health of the individual, such as neuropathy, heart disease, nephropathy, and others (Sanz et al., 2010). This disease has been growing exponentially, reaching around 422 million people worldwide (NCD Risk Factor, 2016). T2DM (90\% of cases) is characterized by muscle cells inability to respond to insulin, causing compensatory responses, generating a state of insulin hypersecretion, which may lead to

* Corresponding Author

Midwest State University (UNICENTRO), Campus CEDETEG, Guarapuava-PR, 85040-080,Brazil; e-mail: lasilva7@ hotmail.com; Tel.: $+554299697341 d$. the development of other chronic degenerative diseases (Weyer et al., 2001; Maiorana et al., 2001; Coughlan et al., 2014).

Therefore, it is necessary to seek therapies that can improve the health of these patients, avoiding the development of subsequent diseases, such as endothelial dysfunctions, cardiac problems, neuropathies, nephropathy, retinopathy, and worsening of clinical and quality of life's patient (Maiorana et al., 2001). Considering that great part of these complications arises from problems in glucose uptake by the cell and accumulation of fatty acids in the bloodstream, the action of AMP-activated protein kinase (AMPK), an enzyme sensitive to intracellular energetic concentrations, stands out. Energy levels are low by stimulating glucose uptake by the cell, oxidation of fatty acids and decreased hepatic glucose production, activation of this protein kinase provides improvements in insulin sensitivity improving metabolic health (Coughlan et al., 2014). 
Pharmacological and physiological strategies that have the principle of AMPK activation are gaining great research interest in the treatment of diseases such as T2DM (Ruderman et al., 2013). Currently, advances in research in the health area allow us to envision positive perspectives for the treatment of this disease based on the interaction between pharmacological factors, such as metformin, which shows improvement in insulin sensitivity and also in therapy based on life, emphasizing the roles of diet and physical exercise for the improvement of the diabetic patient (Bianchi et al., 2017; Sahay and Sahay, 2002).

In this direction, the present study aims to review the available literature on information between the interaction of drug therapy with metformin in conjunction with the practice of physical exercise, focusing on the function of protein kinase activated by AMP (AMPK), pointing out possible mechanisms for This work in synergy.

\section{ROLE OF METFORMIN IN T2DM TREATMENT}

Metformin has been widely used for the treatment of T2DM because of its effect on improving insulin sensitivity. In the class of biguanides, metformin chlorhydrate is a substance derived from guanidine, active compound of the medicinal plant Galega Officinalis (Graham et al., 2011). One of its effects, it is possible to observe partial inhibition of hepatic neoglycogenesis, which is directly linked to a decrease in insulin resistance, leading to a decrease in glucose in the fasted state and increasing the insulin sensitivity of peripheral tissues such as skeletal muscle. It also decreases intestinal glucose uptake and improves glucose uptake and utilization in general (Gosg et al., 2012, Zou et al., 2004).

Sakar et al. (2002) sought to assess whether metformin could regulate intestinal glucose transport and thereby improve insulin sensitivity. As a result, the researchers observed redistribution in glucose transporters, reducing excessive glucose uptake and a consequent improvement in the glucose tolerance test. Considering that the hyperinsulinemia framework can bring several deleterious effects to health, the interest in the use of this drug for general health improvement is gaining great interest by the scientific community. Its clinical application has shown good results in several aspects of health in general, such as reduction of vascular problems (such as stroke, acute myocardial infarction and peripheral vascular disease) (UKPDS, 1998). Marchetti et al. (1998), showed in their work an effect on the alteration in the metabolic process of lipids, increasing the amount of free fatty acids, thus bringing a possible benefit to the mobilization and use of fat as an energy substrate.

Studies indicate that among the positive effects provided by this substance is the activation of AMPK (Ruderman et al., 2013). This activation triggers intracellular cascades and this signaling may mediate many of the beneficial effects noted, such as alteration in gene transcription and stimulatory mechanisms for glucose uptake, such as mitochondrial biogenesis and increase of glucose transporters to the cell membrane (Zou et al., 2004).

Cai et al., (2016) demonstrated in his study with sixty patients diagnosed with endometrial carcinoma that treatment with
Metformin increased the activation of AMPK and that this activation was directly related to the improvement in the individuals' condition. Thus, the use of metformin in addition to improvements in glucose metabolism may provide improvements to other complications resulting from T2DM (Unnikrishnan et al., 2016).

\section{METFORMIN AND AMPK RELATION}

According to Zou et al. (2004), AMPK had increased activation by metformin in hepatocytes and skeletal muscle in rats. In the study by Musi et al. (2003) metformin exerted increased AMPK activity in skeletal muscle in humans.

To understand these mechanisms, some studies have sought to uncover actions of Metformin on AMPK, which could lead to an increase in AMPK activity by metformin, by AMPK threonine 172 phosphorylation. Another way of action of Metformin could be by activation of the liver enzyme kinase B1 (LKB1) and consequently activation of AMPK, by processes not fully understood (Ruderman et al., 2013; Zhou et al., 2001; Hardie, 2003).

In the work of Zang et al. (2004), the main modification caused by metformin in the metabolism of fatty acids is mediated by the activation of AMPK, in which HMGCoA reductase and Acetyl-CoA carboxylase (ACC), inactivation of cholesterol and fatty acids synthesis in hepatocytes Which leads to a decrease in their production and a consequent decrease in lipidemia, a decrease in hepatic steatosis and an increase in the insulin sensitivity of liver cells. The action of metformin on the activation of LKB1 for AMPK stimulation and consequently its cellular actions are illustrated in figure 1.

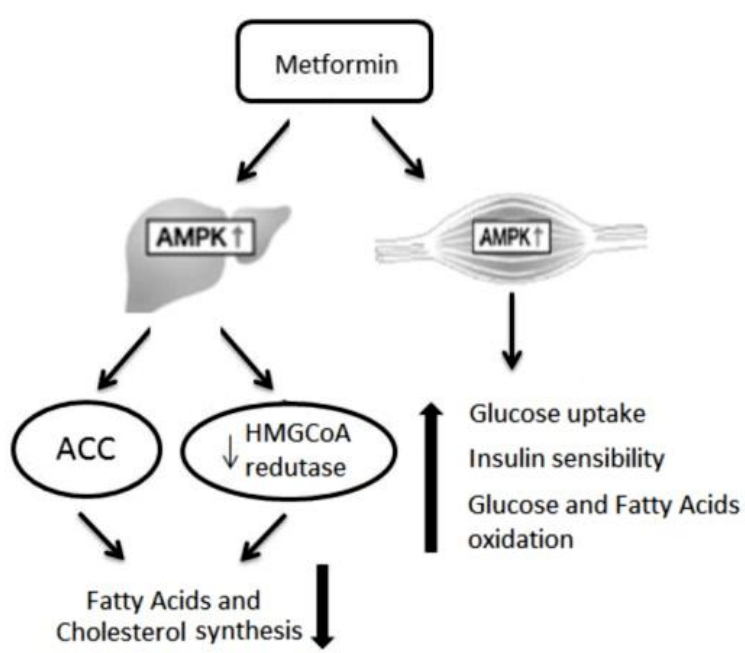

Fig 1: Activation of LKB1 by metformin leading to the subsequent activation of AMPK in several tissues where it is noticed a decrease in the synthesis of fatty acids and cholesterol in the hepatocyte better uptake of glucose by the skeletal muscle and their respective metabolic regulation providing increased sensitivity to insulin.

\section{AMPK AND PHYSICAL EXERCISE RELATION}

The main mechanism proposed by the beneficial effects of physical exercise on glucose metabolism permeates through the 
activation of AMPK (Colberg et al., 2010). To understand these processes, Kemp et al. (2003) found that AMPK is very sensitive to moments that cause a decrease in the energy state of the cell, similarly to what happens in the practice of physical exercise, where successive contractions stimulate energy expenditure, and thus, reduce ATP. AMPK activation is shown in different intensities and durations of physical exercise (McGee and Hargreaves, 2006; Wasserman and Halseth, 1998).

Even with the evidence that AMPK promotes greater uptake of glucose by the skeletal muscle in the contractile process, its role in carbohydrate metabolism is not completely known, some evidence suggests that AMPK regulates glucose and glycogen metabolism, stimulating the glycolytic pathway through Enzymatic activation of phosphofructokinase 2 PFK-2 (Hardie, 2003; Kemp et al, 2003).

\section{PHYSICAL EXERCISE AND METFORMIN ASSOCIATION}

The possible effect of Metformin $(150 \mathrm{mg} / \mathrm{kg} / \mathrm{day})$ and physical exercise $(1 \mathrm{~h} /$ day) on rats reduced serum glucose in relation to control, but when analyzed in isolation, the effects did not show significant differences in biomarkers Such as cholesterol, triglycerides and cholesterol, however, the authors conclude that adding exercise to pharmacological therapies can add beneficial effects to treatment (Tang e Reed, 2001).

According to Malin et al. (2001) observed the association between physical exercise and metformin on AMPK activation in skeletal muscle and observed that this combination could be more effective for stimulation after 12 weeks, interventions improved insulin sensitivity, but the largest increase was observed after Intervention only with exercise and in conclusion the authors suggested that metformin in exercise therapy could attenuate the effects.

Metformin (200mg/day) does not increase insulin sensitivity after physical exercise when compared to exercise alone, and when AMPK activity is evaluated, it was shown 3 times higher after exercise at $65 \% \mathrm{VO}_{2 \max }$, but with no association with metformin (Sharoff et al., 2010).

Based on the evidence that metformin would attenuate the insulin sensitivity promoted by exercise, we sought to evaluate the effects of both on insulin resistance individuals among a group taking their daily dose after exercise. As a result, the researchers found that glucose tolerance was similar to that of the control group, but the energy expenditure during the activity was $9 \%$ higher with the combination with metformin and this was due to the higher oxidation of carbohydrates (Ortega et al., 2014)

\section{FUTURE PERSPECTIVES AND CONCLUSIONS}

Based on the data presented, there are potential mechanisms to obtain benefits of treatment with metformin in combination with exercise for the treatment of T2DM in an efficient manner, however, further research is needed to analyze the effect of the combination on different exercise protocols and different metformin dosages, considering that some studies have observed attenuation of the beneficial effects of exercise to the timing and drug dosages at different times of the day, considering the drug half-life and its active principle so that it is possible to analyze possible daily distributions of exercise and metformin with The purpose of obtaining the best results, allocating each one in the best possible scenario in the treatment of T2DM and its complications.

However, more research is needed with different physical activity protocols, involving intense training, resistance training, high intensity interval training and its combination with metformin to evaluate the respective responses to each exercise.

\section{Financial support and sponsorship: Nil.}

Conflict of Interests: There are no conflicts of interest.

\section{REFERENCES}

Sanz C., Gautier JF., Hanaire H. Physical exercise for the prevention and treatment of type 2 diabetes. Diabetes Metab, 2010; 36(5):346-51. doi: 10.1016/j.diabet.2010.06.001.

NCD Risk Factor Collaboration. Worldwide trends in diabetes since 1980: a pooled analysis of 751 population-based studies with 4.4 million participants. Lancet, 2016; 387(10027): 1513-1530.

Weyer C., Funahashi T., Tanaka S., Hotta K., Matsuzawa Y., Pratley RE., Tataranni PA. Hypoadiponectinemia in obesity and type 2 diabetes: close association with insulin resistance and hyperinsulinemia. J Clin Endocrinol Metab, 2001; 86(5):1930-5.

American Diabetes Association. Diagnosis and classification of diabetes mellitus. Diabetes care, 2006; 29(1):43-44.

Maiorana A., O'Driscoll G., Cheetham C., Dembo L., Stanton K., Goodman C., Taylor R., Green D. The effect of combined aerobic and resistance exercise training on vascular function in type 2 diabetes. $\mathrm{J}$ Am Coll Cardiol, 2001 Sep;38(3):860-6.

Coughlan KA., Valentine RJ., Ruderman NB., Saha AK. AMPK activation: a therapeutic target for type 2 diabetes? Diabetes, Metabolic Syndrome and Obesity: Targets and Therapy, 2014;7:241-253. doi:10.2147/DMSO.S43731.

Ruderman NB., Carling D., Prentki M., Cacicedo JM. AMPK, insulin resistance, and the metabolic syndrome. J Clin Invest, 2013; 123(7):2764-72. doi: 10.1172/JCI67227.

Bianchi C., Daniele G., Dardano A., Miccoli R., Del Prato S. Early Combination Therapy with Oral Glucose-Lowering Agents in Type 2 Diabetes. Drugs, 2017; 77(3):247-264. doi: 10.1007/s40265-017-0694-4.

Sahay BK., Sahay RK. Lifestyle modification in management of diabetes mellitus. J Indian Med Assoc, 2002; 100(3):178-80.

Graham GG., Punt J., Arora M., Day RO., Doogue MP., Duong JK., Furlong TJ., Greenfield JR., Greenup LC., Kirkpatrick CM., Ray JE., Timmins P., Williams KM. Clinical pharmacokinetics of metformin. Clin Pharmacokinet, 2011; 50(2):81-98. doi: 10.2165/11534750-00000000000000 .

Gong L., Goswami S., Giacomini KM., Altman RB., Klein TE. Metformin pathways: pharmacokinetics and pharmacodynamics. Pharmacogenet Genomics, 2012; 22(11):820-7. doi: 10.1097/FPC.0b013e3283559b22.

Zou MH., Kirkpatrick SS., Davis BJ., Nelson JS., Wiles WG., Schlattner U. Activation of the AMP-activated protein kinase by the antidiabetic drug metformin in vivo - role of mitochondrial reactive nitrogen species. J Biol Chem, 2004;279:43940-51.

Sakar Y., Meddah B., Faouzi M., Cherrah Y., Bado A., Ducroc R. Metformin-induced regulation of the intestinal D-glucose transporter. J Indian Med Assoc, 2002;100(3):178-80.

UK Prospective Diabetes Study - UKPDS. Group: Effect of intensive blood glucose control with metformin on complications in overweight patients with type 2 diabetes (UKPDS 34). Lancet, 1998; 352(9131): 854-65. 
Marchetti P., Benzi L., Cerri M., Cecchetti P., Giannarelli R., Giannecchini M. Effect of plasma metformin concentrations on serum lipid levels in type II diabetic patients. Acta Diabetol Lat, 1988; 25:55-62.

Cai D., Sun H., Qi Y., Zhao X., Feng M., Wu X. Insulin-Like Growth Factor 1/Mammalian Target of Rapamycin and AMPActivated Protein Kinase Signaling Involved in the Effects of Metformin in the Human Endometrial Cancer. Int J Gynecol Cance, 2016; 26(9):1667-1672.

Unnikrishnan R. Metformin Beyond Diabetes. In: RSSDI Diabetes Update 2016. Jaypee, pp. 123-126.

Musi N., Goodyear LJ. AMP-activated protein kinase and muscle glucose uptake. Acta Physiol Scand, 2003; 178:337-45.

Zhou G., Myers R., Li Y., Chen Y., Shen X., Fenyk-Melody J. Role of AMP-activated protein kinase in mechanism of metformin action. J Clin Invest, 2001; 108:1167-74.

Hardie DG. Minireview: the AMP-activated protein kinase cascade: the key sensor of energy status. Endocrinology, 2003; 144:517983.

Zang M., Zuccolo A., Hou X., Nagata D., Walsh K., Herscovitz H. AMP-activated protein kinase is required for the lipid-lowering effect of metformin in insulin-resistant human HepG2 cells. J Biol Chem, 2004; 279:47898-905.

Colberg SR., Sigal RJ., Fernhall B., Regensteiner JG., Blissmer BJ., Rubin RR., Chasan-Taber L., Albright AL., Braun B. Exercise and Type 2 Diabetes: The American College of Sports Medicine and the American Diabetes Association: joint position statement. Diabetes Care, 2010;33(12):e147-e167. doi:10.2337/dc10-9990.

Kemp BE., Stapleton D., Campbell DJ., Chen ZP., Murthy S., Walter M., Gupta A., Adams JJ., Katsis F., van Denderen B., Jennings IG., Iseli T., Michell BJ., Witters LA. AMP-activated protein kinase, super metabolic regulator. Biochem Soc Trans, 2003;31:162-8.

McGee SL., Hargreaves M. Exercise and skeletal muscle glucose transporter 4 expression: molecular mechanisms. Clin Exp Pharmacol Physiol, 2006; 33(4):395-9.

Wasserman DH., Halseth AE. An overview of muscle glucose uptake during exercise. Sites of regulation. Adv Exp Med Biol, 1998; 441:1-16
Tang T., Reed MJ. Exercise adds to metformin and acarbose efficacy in db/db mice. Metabolism, 2001;50(9):1049-53.

Malin SK., Gerber R., Chipkin SR., Braun B. Independent and combined effects of exercise training and metformin on insulin sensitivity in individuals with prediabetes. Diabetes Care, 2001; 35(1):131-6. doi: 10.2337/dc11-0925.

Sharoff CG., Hagobian TA., Malin SK., Chipkin SR., Yu H., Hirshman MF., Goodyear LJ., Braun B. Combining short-term metformin treatment and one bout of exercise does not increase insulin action in insulin-resistant individuals. Am J Physiol Endocrinol Metab, 2010; 298(4): 815-23. doi: 10.1152/ajpendo.00517.2009.

Ortega JF., Hamouti N., Fernández-Elías VE., de Prada MV., Martínez-Vizcaíno V., Mora-Rodríguez R. Metformin does not attenuate the acute insulin-sensitizing effect of a single bout of exercise in individuals with insulin resistance. Acta Diabetol, 2014 Oct;51(5):749-55. doi: 10.1007/s00592-014-0580-4.

\section{How to cite this article:}

Oliveira LEC, Silva LA, Wouk J, Weber VM, Eltchechem CL, Almeida P, Martins JCL, Martins FAS, Malfatti CRM, Osiecki R. Role of AMPK and its possible interactions in metformin therapy and physical exercise - Research perspectives. J App Pharm Sci, 2017; 7 (10): 196-199. 